\title{
Effects of Lidocaine Infusion on Quality of Recovery and Agitation after Functional Endoscopic Sinus Surgery: Randomized Controlled Study
}

\author{
Rehab Abd Elraof Abd Elaziz, Shahenda Shaban, Shaker Abd Elaziz \\ Department of Anesthesia and Surgical Intensive Care, Faculty of Medicine, Alexandria University, Alexandria, Egypt \\ Email: trcium2002@yahoo.com
}

How to cite this paper: Elaziz, R.A.E.A., Shaban, S. and Elaziz, S.A. (2020) Effects of Lidocaine Infusion on Quality of Recovery and Agitation after Functional Endoscopic Sinus Surgery: Randomized Controlled Study. Open Journal of Anesthesiology, 10, 435-448. https://doi.org/10.4236/ojanes.2020.1012038

Received: November 20, 2020

Accepted: December 26, 2020

Published: December 29, 2020

Copyright ( 2020 by author(s) and Scientific Research Publishing Inc. This work is licensed under the Creative Commons Attribution International License (CC BY 4.0).

http://creativecommons.org/licenses/by/4.0/ (c) (i) Open Access

\begin{abstract}
Background: After functional endoscopic nasal surgery, emergence agitation is not uncommon. The aim of this trial was to investigate the effect of perioperative lidocaine infusion on postoperative early recovery quality and incidence of emergence agitation in patient undergoing functional endoscopic sinus surgery. Study Design: Prospective, randomized, double-blinded, placebo-controlled trial. Methods: 100 patients of ASA I and II, aged 18 - 50 years, of both sexes scheduled for FEES, were assigned into two groups. In Group L; patients received an intravenous bolus infusion of $1.5 \mathrm{mg} / \mathrm{kg}$ lidocaine just before induction of anesthesia followed by a continuous infusion of $2 \mathrm{mg} / \mathrm{kg} / \mathrm{h}$ during the operation and until the end of the surgery. In Group C; patients received normal saline infusion with the same volume as group L according to the same protocol. The primary endpoints were incidence of emergence agitation and postoperative recovery quality (QoR-40) score on first postoperative day (POD1). Results: Incidence of emergence agitation was significantly lower in group L $(P<0.05)$ compared with group C. Global QoR-40 scores on POD1 were significantly lower in both groups compared with preoperative assessment, it was significantly higher in group L on POD1 $(P<0.05)$ than in group C. Among the five dimensions of QoR-40, the scores for physical comfort and pain were superior in group $\mathrm{L}$ compared to group $\mathrm{C}$ $(P<0.05)$ at POD1. Conclusion: Systemic lidocaine infusion can improve QoR-40 scores and decrease incidence of emergence agitation in patients scheduled for FEES, also it reduces the duration of stay in PACU after surgery.
\end{abstract}

\section{Keywords}

Lidocaine, Quality of Recovery-40 Questionnaire, Emergence Agitation, FEES 


\section{Introduction}

Functional endoscopic sinus surgery (FEES) is a common surgical procedure in the otorhinolaryngology specialty for symptomatic improvement in patients with medically refractory chronic rhinosinusitis and chronic polypous rhinosinusitis [1].

The essential anesthesia requirements for FESS include airway management, considerations for facilitating surgical access, provision of a clear and still surgical field for precision surgery, assuring quick and non-stimulating emergence from anesthesia, and fast-tracking patients for discharge [2].

Postoperative recovery which is defined as the patients return to the normal state after a surgery is the key outcome in the perspective of anesthesiologists. In the past it has been referred in terms of pain scores, duration of hospital stay, and return to normal activities [3]. But now it involves several factors such as regain of physical, physiologic and social functions. Therefore, it is fundamental for the evaluation of health care and patient satisfaction after surgery [4] [5].

A valid and reliable measure of quality of recovery (QoR) after anesthesia and surgery was developed by Myles et al. It has shown superior content validity and constructs validity, when compared to other pre-existing questionnaires. The Quality of Recovery-40 (QoR-40) questionnaire is a reliable and accurate multidimensional assessment tool used to evaluate the status of patients after anesthesia [6]. QoR-40 is a global measure of quality of recovery incorporating five dimensions of health; psychological support, physical comfort, emotions, physical independence, and pain; each item is graded on a 5-point Likert scale, (none of the time, some of the time, usually, most of the time, and all of the time). The scores range from 40 (extremely poor quality of recovery) to 200 (excellent quality of recovery). QoR-40 is well suited to measure quality of postoperative recovery; poor quality of recovery can predict a poor quality of life after surgery [7] [8]. Prolonged recovery after surgery can lead to delayed hospital discharges and increased costs which can impact resource utilization and mitigate patient satisfaction [9].

Emergence agitation (EA) after nasal surgery is a common phenomenon [10] [11]. Patients undergoing nasal surgery commonly complain of a sense of suffocation due to intranasal packing and manifest agitation during emergence which can lead to several problems, such as injury to the patient or medical staff, unplanned removal of a catheter or endotracheal tube, re-bleeding at the operation site, and delayed discharge [12] [13]. There are many independent risk factors for EA such as pain, endotracheal intubation, duration of surgery, and history of treatment by antidepressant agents. It is commonly observed in younger patients with lower American Society of Anesthesiologist scores [14].

Several pharmacological methods have been used to mitigate EA, including opioid (fentanyl, remifentanil), propofol, benzodiazepine (midazolam), $\alpha_{2}$ aderenoreceptor agonist (clonidine, dexmedetomidine), and $\mathrm{N}$-methy-d-aspartate (NMDA) receptor antagonist (ketamine, magnesium sulfate) administration 


\section{[15] [16].}

Lidocaine is an amino amide-type short-acting local anesthetic (LA). It has a short half-life, and a favorable safety profile, and is therefore the LA of choice for continuous IV administration [17]. Systemic lidocaine has been shown to be an effective adjunct strategy to reduce postoperative pain [18] [19] [20]. We hypothesized that systemic infusions of lidocaine may improve postoperative recovery by reducing postoperative pain. The main objective of the current study was to evaluate the effect of systemic continuous lidocaine infusion in patients undergoing FESS procedure as regards to quality of postoperative recovery, emergence agitation incidence and time to discharge from postoperative care unit (PACU).

\section{Patients and Methods}

\subsection{Patients}

This prospective, randomized, comparative, controlled study was conducted on 100 adult patients, of both sexes, admitted to Alexandria Main University Hospital, Department of ENT Surgery. Patients were scheduled for elective functional endoscopic sinus surgery, selected to be ASA class I-II., aged (20 - 50 years). The sample size was statistically approved by the biostatistics department of High Institute of Public Health, Alexandria University. The study was registered at ClinicalTrials.gov (NCT04472689). Patients with body mass index >35 $\mathrm{kg} / \mathrm{m}^{2}$, history of allergic reaction to local anesthetic agents especially lignocaine, history of preoperative use of opioids, history of uncontrolled hypertension, $\mathrm{A}-\mathrm{V}$ conduction block, Psychotropic drugs and history of obstructive sleep apnea were excluded from the study. Patients were randomly classified into two equal groups; fifty patients each using closed envelope technique. Lidocaine group, group (L), patients received a loading dose of IV lidocaine $1.5 \mathrm{mg} / \mathrm{kg}$ slowly just before induction of anesthesia, then the lidocaine infusion started at a rate of 2 $\mathrm{mg} / \mathrm{kg} / \mathrm{h}$. Control group, group (C), patients received an equal volume of $0.9 \%$ sodium chloride as the Lidocaine group (both the loading, and the infusion). The infusion in both groups was started just after induction of anesthesia induction and continued until the end of the operation. Approval of Ethical Committee of the Faculty of Medicine, Alexandria University was taken and an informed written consent was taken from each patient.

\subsection{Methodology}

Every patient in the study was subjected to a careful pre-anesthetic assessment including history taking as regards current medical illnesses and drug therapy, thorough clinical examination, and routine laboratory investigations. Before induction of anesthesia, standard monitoring was implemented. A bolus of lidocaine in group (L) and bolus of 0.9 normal saline in group (C ) were given over 10 minutes, then anesthesia was induced with fentanyl $2 \mu \mathrm{g} \cdot \mathrm{kg}^{-1}$, propofol 2 $\mathrm{mg} \cdot \mathrm{kg}^{-1}$ followed by atracurium $0.5 \mathrm{mg} \cdot \mathrm{kg}^{-1}$ to facilitate tracheal intubation and 
throat pack was inserted under vision with indirect laryngoscopy. Mechanical ventilation was started to maintain end-tidal carbon dioxide between 32 and 36 $\mathrm{mmHg}$. Anesthesia was maintained with an inspired sevoflurane concentration of 1 - $2 \mathrm{MAC}$ in AIR/O $/ 2$ mixture $\left(1 / 1 \mathrm{l} \cdot \mathrm{min}^{-1}\right)$. Neuromuscular block was maintained with atracurium $0.2 \mathrm{mg} \cdot \mathrm{kg}^{-1} \cdot \mathrm{h}^{-1}$ as needed. Using multichannel (Dräger Infinity Vista XL; Drägerwerk AG \& Co., Lübeck 23558, Germany) monitor, patients were continuously monitored for noninvasive arterial blood pressure, lead II electrocardiography, heart rate, arterial oxygen saturation, inspired and end-tidal concentrations of sevoflurane, end tidal carbon dioxide, inspired and end-tidal concentrations of oxygen. Also, ventilatory monitoring for mean airway pressure peak airway pressure and minute ventilation were monitored. Continuous infusions of lidocaine and normal saline were started in both groups as mentioned till the end of surgery.

Intravenous paracetamol $1 \mathrm{~g}$ was administered in all the cases 15 min before expected time for extubation for postoperative analgesia. After the completion of surgery, suctioning of airways and oral cavity were done and the throat pack was removed. Patients received neostigmine $50 \mu \mathrm{g} \cdot \mathrm{kg}^{-1}$, given intravenously with atropine $1 \mathrm{mg}$ after testing of neuromuscular block by means of a nerve stimulator with a train-of-four ratio (TOF) more than 0.7. Infusions of lidocaine and saline were stopped, patients were extubated and transferred to the PACU.

Incidence of emergence agitation was evaluated at zero time then at $15 \mathrm{~min}$. and $30 \mathrm{~min}$. after arrival to PACU using the Richmond Agitation-Sedation Scale (RASS). (RASS: +4 , combative; +3 , very agitated; +2 , agitated; +1 , restless; 0 , alert and calm; -1 , drowsy; -2 , light sedation; -3 , moderate sedation; -4 , deep sedation; -5, unarousable) [21] EA was defined as any RASS score $\geq+2$. Observers who recorded data were blinded with respect to patients' group allocation. Quality of postoperative functional recovery was assessed using the QoR-40 questionnaire; it was evaluated the day before surgery and 24 hours postoperatively through telephone by an investigator unaware of group allocation. Patients were questioned by using QoR-40 questionnaire that assess five dimensions of recovery: physical comfort (12 items), emotional state (9 items), physical independence (5 items), psychological support (7 items), and pain (7 items). Each item was rated on a five-point Likert scale: (none of the time, some of the time, usually, most of the time, and all of the time). The total score on the QoR-40 ranges from 40 (poorest quality of recovery) to 200 (best quality of recovery). The total score was calculated for each patient [22] [23].

\subsection{Statistical Analysis}

\subsubsection{Sample size}

Based on literature review, a total sample of 100 patients (50 per group) is required to assess an average difference at QOR-40 score of $13 \pm 5$ point $(1-3)$. The sample size was estimated using PASS software at $95 \%$ confidence level and study power of $80 \%$ and $10 \%$ for attrition rate [24]. 


\subsubsection{Data Analysis}

After data was extracted, it was revised, coded, and fed to statistical software IBM SPSS version 22 (SPSS, Inc. Chicago, IL). All statistical analysis was done using two tailed tests. $\mathrm{P}$ value less than 0.05 was statistically significant. Scale data normality was assessed using Shapiro test. Descriptive analysis based on frequency and percent distribution for categorical data (demographics and agitation) was used where mean with standard deviation was used to describe scale data including time and QOR-40 scores. Discrete scores for different QOR-40 scale domain were summed to have an overall score for each of the five domains and the grand total for the scale. Comparing distribution of agitation among the study groups was assessed using exact probability test due to small expected frequencies. Time to discharge from PACU, and QOR-40 scores were compared between the study groups using parametric independent samples t-test. Paired t-test was used to compare means scores of QOR- 40 within the same group before and 24 hours after operation [25] [26].

\section{Results}

A total of 120 patients were initially enrolled in the study, six of whom were excluded, and fourteen patients were unable to complete the scoring after surgery. Therefore, the final sample size was 100 patients (Figure 1). There were no clinically important differences in demographic data, ASA classification or duration of surgery between the two groups (Table 1).

Table 1. Bio-demographic data of the study groups\& surgery duration.

\begin{tabular}{cccc}
\hline Personal data & Group I & Group II & P-value \\
\hline Age in years & & & \\
Range & $22-50$ & $25-48$ & \\
Mean \pm SD & $36 \pm 10$ & $35 \pm 8$ & 0.756 \\
\hline Sex (male/female) & $35 / 15$ & $32 / 18$ & 0.861 \\
\hline Height (cm) & $160-185$ & $156-190$ & \\
Range & $172 \pm 11$ & $173 \pm 14$ & 0.706 \\
Mean \pm SD & & & \\
\hline Weight (kg) & $55-90$ & $70 \pm 15$ & 0.779 \\
Range & $72 \pm 14$ & $41 / 9$ & \\
Mean \pm SD & $38 / 12$ & $80-135$ & \\
\hline ASA (I/II) & $105 \pm 12$ & $107 \pm 24$ & \\
\hline Surgery time (minutes) & & & \\
Range & $90-120$ & & \\
\hline Mean \pm SD & & & \\
\hline
\end{tabular}




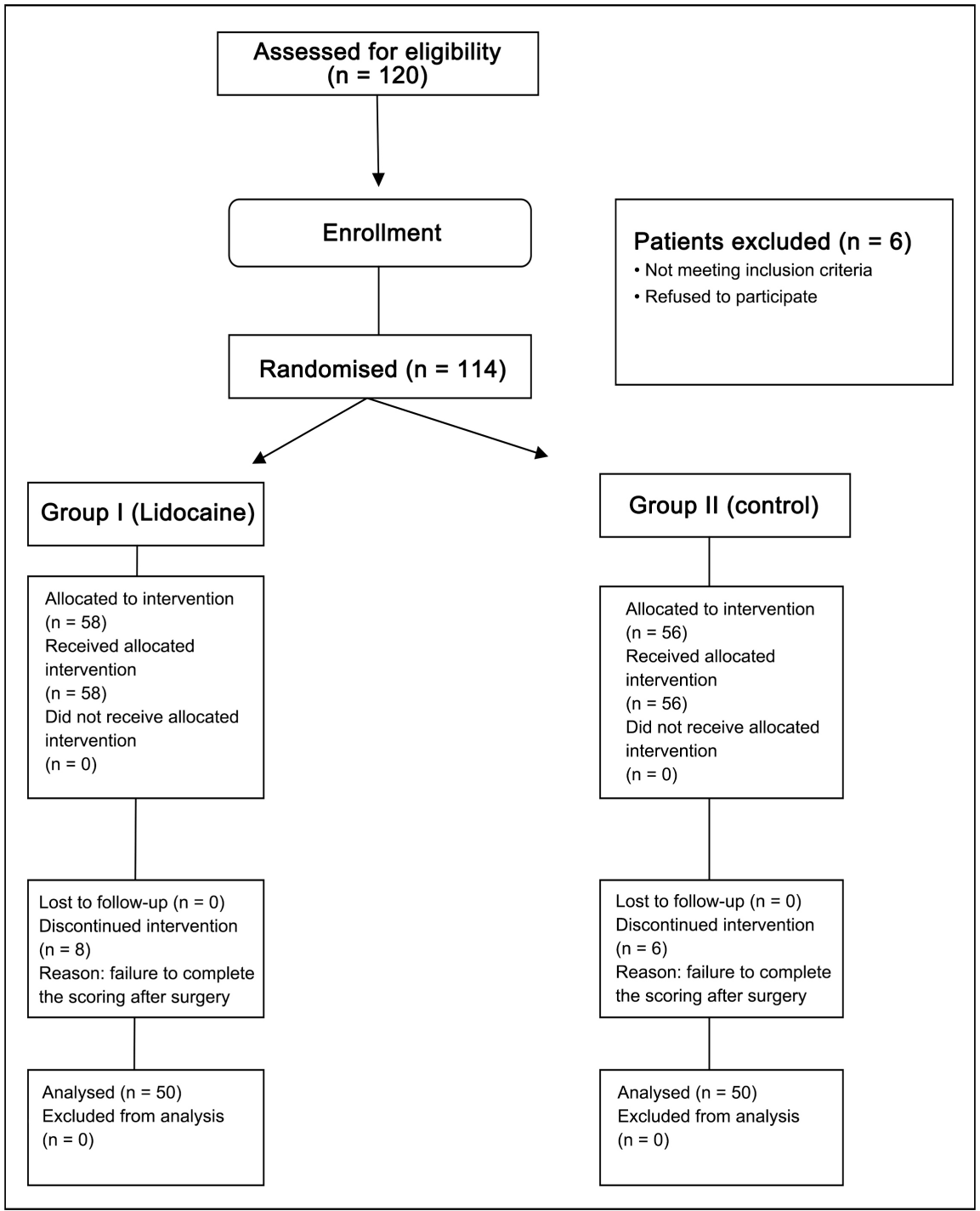

Figure 1. Consort 2010 flow diagram of the study.

According to emergence agitation incidence as shown in Table 2, the RSAS during emergence differed significantly between the 2 groups, it was significantly lower in lidocaine group 30\% (15 agitated and 35 non-agitated) compared with $50 \%$ (25 agitated and 25 non-agitated) in the control group at zero time on admission to PACU $(P<0.036)$, also, it was significantly lower in lidocaine group 14\% (7 agitated and 43 non-agitated) compared with 30\% (15 agitated and 35 non-agitated) in the control group at 15 minutes time on admission to PACU ( $P$ $<0.047)$ and no significant difference between both groups at 30 minutes after arrival to PACU $(P<0.125)$.

The distribution of pre- and postoperative global QoR- 40 scores and the score of each dimension are shown in Table 3. Preoperatively global QoR-40 score was comparable between the two groups without significant difference $(P=$ 0.33). Postoperatively global QoR-40 scores were significantly decreased compared with preoperative scores in both groups $(P=0.001$ in group $\mathrm{L}$ and group 
C). A significant difference $(P=0.037)$ in QoR-40 scores was observed between the two groups on POD1 with significant decrease in control group compared to lidocaine group. The patients in group L showed a significantly lesser decline in global QoR-40 in POD1. Among the five dimensions of the QoR-40, physical comfort, emotional status and pain scores were significantly higher in the lidocaine group compared with the control group on POD1 without significant difference preoperatively.

The distribution of PACU time is shown in Table 4 , it was significantly shorter in lidocaine group compared to control group $(P=0.001)$.

Table 2. Distribution of agitation among study groups.

\begin{tabular}{cccccc}
\hline \multirow{2}{*}{ Time } & \multicolumn{3}{c}{ Group I } & \multicolumn{3}{c}{ Group II } & \multirow{2}{*}{ P-value } \\
\cline { 2 - 5 } & No & $\%$ & No & $\%$ & \\
\hline 0 time & 15 & 30 & 25 & 50 & $0.036^{\star}$ \\
15 min & 7 & 14 & 15 & 30 & $0.047^{\star}$ \\
30 min & 3 & 6 & 7 & 14 & 0.125 \\
\hline
\end{tabular}

P: Exact probability test. ${ }^{*} P<0.05$ (significant).

Table 3. Distribution of quality of recovery among study groups at different study phases.

\begin{tabular}{|c|c|c|c|c|}
\hline \multirow{2}{*}{ Phase } & \multirow{2}{*}{ Parameter } & Group I & Group II & \multirow{2}{*}{$P$-value } \\
\hline & & Mean \pm SD & Mean \pm SD & \\
\hline \multirow{7}{*}{ Pre-operative } & emotional status & $41 \pm 5$ & $42 \pm 6$ & 0.324 \\
\hline & physical comfort & $57 \pm 6$ & $57 \pm 6$ & 0.442 \\
\hline & psychological support & $33 \pm 4$ & $34 \pm 4$ & 0.826 \\
\hline & & & & \\
\hline & Physical independence & $24 \pm 3$ & $25 \pm 4$ & 0.885 \\
\hline & pain & $34 \pm 4$ & $34 \pm 3$ & 0.890 \\
\hline & TotalQoR40 & $183 \pm 16$ & $185 \pm 17$ & 0.335 \\
\hline \multirow{6}{*}{$\begin{array}{c}24 \text { hours } \\
\text { post-operative }\end{array}$} & emotional status & $38 \pm 4$ & $33 \pm 3$ & $0.027^{*}$ \\
\hline & physical comfort & $53 \pm 5$ & $50 \pm 5$ & $0.044^{*}$ \\
\hline & psychological support & $28 \pm 3$ & $27 \pm 3$ & 0.230 \\
\hline & Physical independence & $20 \pm 3$ & $18 \pm 3$ & 0.108 \\
\hline & pain & $26 \pm 3$ & $22 \pm 3$ & $0.010^{*}$ \\
\hline & TotalQoR40 & $171 \pm 13$ & $157 \pm 12$ & $0.037^{*}$ \\
\hline$P$-value ${ }^{\#}$ & & $0.001^{* *}$ & $0.001^{*}$ & \\
\hline
\end{tabular}

P: independent samples t-test; \#: Paired t-test; ${ }^{*} P<0.05$ (significant); ${ }^{* *} P<0.01$ (significant). 
Table 4. Distribution of time to discharge from PACU (minutes) according to study groups.

\begin{tabular}{cccc}
\hline Time & Group I & Group II & P-value \\
\hline Range & $35-75$ & $35-90$ & \\
Mean \pm SD & $54.2 \pm 11.1$ & $67.5 \pm 12.8$ & $0.001^{\star *}$ \\
Median & 55 & 70 & \\
\hline
\end{tabular}

P: independent samples t-test; ${ }^{* *} P<0.01$ (significant).

\section{Discussion}

Postoperative pain after nasal surgery could be as a result many factors as intraoperative tissue injury, inflammation, nerve stimulation, and postoperative swelling, many inter-related postoperative events may provoke agitation, including postoperative pain and hypoxemia, Pain not only causes postoperative complications but also causes psychological stress and anxiety, which further aggravate postoperative pain consequently causing delayed postoperative recovery [27]. The exact etiological mechanism of EA has yet to be elucidated as multiple pathophysiological abnormalities in dopaminergic, noradrenergic, serotonergic, and $\gamma$-aminobutyric acid pathways have been suggested to be associated with the etiology of agitation. In adults, endothelial dysfunction due to the release of inflammatory cytokines is a common perioperative event and a crucial factor influencing the incidence of delirium, A possible explanation is that NMDA postsynaptic potential-induced excitatory hyperactivity at the thalamolateral nucleus of the amygdala synapse enhances the uncomfortable stimuli-induced behavior [28] [29]. Although EA can occur after minimal or non-painful surgeries, pain is a major risk factor of EA [30].

Administration of intravenous lidocaine in perioperative period produces analgesia by different ways; as it may cause an increase in concentration of acetylcholine in cerebrospinal fluid, leading to exacerbation of inhibitory descending pain pathway, blocking of muscarinic receptors $M 3$, inhibition of glycine receptors, release of endogenous opioids, reduction of the inflammatory response to tissue ischemia, and decreased release of cytokines in response to tissue damage. Lignocaine is also responsible for direct or indirect reduction of postsynaptic depolarization mediated by $\mathrm{N}$-methyl-D-aspartate receptors [31]-[36].

Nasal surgery is significantly associated with a higher incidence of EA compared to other types of surgery, Kim et al. reported that the occurrence of emergence agitation could be as high as $55.4 \%$, and the presence of nasal pack is likely to be the main trigger of agitation. Elseryreported an incidence of $68 \%$ following nasal surgery [37] [38].

The present study demonstrated a significant decrease in the incidence of emergence agitation in patients received lidocaine infusion compared with those received saline infusion during anesthesia for FEES.

Tauzin-Fin and Bernard studied the effect of adding lignocaine infusion to 
standard anesthesia protocol in a total of 47 patients planned for laparoscopic nephrectomy. Lignocaine infusion was continued for $24 \mathrm{~h}$ postoperatively and was associated with significant reduced morphine consumption and postoperative pain score [39]. Previous studies support this suggestion, adequate postoperative pain control using potent analgesics, such as fentanyl or remifentanil, showed efficacy in reducing EA, but weak analgesics and nonsteroidal anti-inflammatory drugs such as ketorolac alone did not reduce EA after anesthesia [40] [41] [42].

In a study carried out by Rahimzadeh et al. [43] propofol lidocaine anesthesia regimen reduced the incidence of sevoflurane-induced agitation in children with retinoblastoma. In against to our results, in a study was done by Christian P. Both et al. [44], there was a non-significant difference in the incidence of emergence delirium observed between lidocaine group and control group in pediatric patients scheduled for laparoscopic appendectomy under general anesthesia. Young Ho Jang et al. [45] founded that $1.5 \mathrm{mg} / \mathrm{kg}$ of IV lidocaine 5 minutes before extubation did not reduce the incidence of EA and the severity of postoperative pain After sevoflurane anesthesia and the time to discharge from the PACU was similar to that with placebo.

The postoperative quality of recovery-40 (QoR-40), developed and validated by Myles et al. in 2000, is one of the most commonly used instruments to assess postoperative quality of recovery in clinical practice. It was supposed that a 10-pointdifference or more represents clinically relevant improvement in the quality of recovery [6]. Recently, Myles et al. reported that a change of 6.3 in the global QoR-40 can signify a clinically important improvement or deterioration [46].

In the current study our results showed that the global QoR-40 scores were significantly lower in both groups at POD1 compared to preoperative measurements suggesting that the surgery and anesthesia had significant effects on the postoperative quality of life. However, the decline of scores in group L was significantly less than that in group $\mathrm{C}$ therefore the postoperative quality of life in group L was superior than in group C. Comparing both groups at POD1 the global QoR-40 score was significantly higher in group L than in group C. Meanwhile, among the five dimensions of the QoR-40, physical comfort, emotional state and pain scores were superior in group L compared to group C. Therefore, our results indicate that intravenous lidocaine leads to significantly better quality of recovery by preventing physiologic deterioration related to anesthesia and surgery. These results consistent with that done by Wang Q et al. [47], they assessed effect of intravenous lidocaine infusion on postoperative early recovery quality at POD1 and POD2 in upper airway surgery, they founded that global QoR-40 scores on POD1 and POD2 were significantly lower compared with the preoperative measurement in both groups. Global QoR-40 scores were significantly higher in lidocaine group on POD1 and POD2compared with control group. Among the five dimensions of QoR-40, the scores for physical 
comfort, emotional state, and pain were superior in group L compared to group C.

Lee et al. [48] reported that systemic infusion of lidocaine during bimaxillary surgery reduces postoperative pain and analgesic consumption and relieves facial swelling. Our results were similar to these findings, as the pain dimension score was superior in group L than in group C, similar results reported by Kim $\mathrm{MH}$, et al. [49] where lidocaine administered intravenously during anesthesia for thyroid surgery in female patients led to better quality of postoperative recovery measured by QoR-40 compared with the control group. Systemic lidocaine improves postoperative quality of recovery in patients undergoing outpatient laparoscopy with less opioid consumption [23].

PONV is a common complication after general anesthesia, with an incidence of up to $20 \%$ to $30 \%$. It can affect patient satisfaction and can even lead to serious complications, such as aspiration and asphyxia, reducing the quality of postoperative early recovery [50]. In our study physical comfort dimension that includes nausea and vomiting as sub-dimensions was superior in group $\mathrm{L}$ than in group C. Likewise, Kim et al. [50] found that in addition to reducing postoperative pain, lidocaine can also quickly restore gastrointestinal function and reduce PONV through both physical and psychological mechanisms. Lidocaine is known to induce fast return of bowel function and reduce nausea/vomiting. These effects can contribute to better postoperative recovery, both physically and emotionally [51].

Our study demonstrated shorter discharge to from PCAU with use of perioperative lignocaine than in the control group. This may be a result of pharmacological effects of lignocaine on inflammation, analgesic requirement, and nausea/vomiting [48].

\section{Conclusion}

Systemic lidocaine infusion can improve QoR-40 scores and decrease incidence of emergence agitation in patients scheduled for FEES, also it reduces the duration of stay in PACU after surgery thus improving the quality of early recovery after surgery.

\section{Acknowledgements}

No external funding or competing interests declared. The study was supported from anesthesia department (Alexandria University, Egypt).

\section{Conflicts of Interest}

The authors declare no conflicts of interest regarding the publication of this paper.

\section{References}

[1] Tan, Y. and Ruban, P. (2014) Anaesthetic Concerns for Functional Endoscopic Si- 
nus Surgery. Proceedings of Singapore Healthcare, 23, 3. https://doi.org/10.1177/201010581402300310

[2] Amit, S. and Vladimir, N. (2020) Anesthetic Considerations for Functional Endoscopic Sinus Surgery: A Narrative Review. Journal of Head \& Neck Anesthesia, 4, 25. https://doi.org/10.1097/HN9.0000000000000025

[3] Luís, G., Maria, C., Gabriela, S. and Fernando, A. (2016) Quality of Recovery after Anaesthesia Measured with QoR-40: A Prospective Observational Study. Brazilian Journal of Anesthesiology, 66, 369-375. https://doi.org/10.1016/j.bjane.2014.11.010

[4] Bowyer, A., Jakobsson, J. and Ljungqvist, O. (2014) A Review of the Scope and Measurement of Postoperative Quality of Recovery. Anaesthesia, 69, 1266-1278. https://doi.org/10.1111/anae.12730

[5] Kluivers, K.B., Riphagen, I. and Vierhout, M.E. (2008) Systematic Review on Recovery Specific Quality-of-Life Instruments. Surgery, 143, 206-215.

https://doi.org/10.1016/j.surg.2007.08.017

[6] Myles, P.S., Weitkamp, B. and Jones, K. (2000) Validity and Reliability of a Postoperative Quality of Recovery Score: The QoR-40. British Journal of Anaesthesia, 84, 11-15. https://doi.org/10.1093/oxfordjournals.bja.a013366

[7] Harish, S.K., Asthana, V. and Agrawal, S. (2019) Evaluation of Lignocaine Infusion on Recovery Profile, Quality of Recovery, and Postoperative Analgesia in Patients Undergoing Total Abdominal Hysterectomy. Journal of Anaesthesiology Clinical Pharmacology, 35, 528-532. https://doi.org/10.4103/joacp.JOACP $209 \quad 18$

[8] Gornall, B.F., Myles, P.S. and Smith, C.L. (2013) Measurement of Quality of Recovery Using the QoR-40: A Quantitative Systematic Review. British Journal of Anaesthesia, 111, 161-169. https://doi.org/10.1093/bja/aet014

[9] Poitras, S., Beaule, P.E. and Dervin, G.F. (2012) Validity of a Short-Term Quality of Life Questionnaire in Patients Undergoing Joint Replacement: The Quality of Recovery-40. The Journal of Arthroplasty, 27, 1604-1608. https://doi.org/10.1016/j.arth.2012.03.015

[10] Yu, D., Chai, W., Sun, X. and Yao, L. (2010) Emergence Agitation in Adults: Risk Factors in 2,000 Patients. The Canadian Journal of Anesthesia, 57, 843-848. https://doi.org/10.1007/s12630-010-9338-9

[11] Jee, Y.S., You, H.J., Sung, T.Y., et al. (2017) Effects of Nefopam on Emergence Agitation after General Anesthesia for Nasal Surgery: A Prospective, Randomized, and Controlled Trial. Medicine, 96, 8843. https://doi.org/10.1097/MD.0000000000008843

[12] Munk, L., Andersen, G. and Moller, A.M. (2016) Post-Anaesthetic Emergence Delirium in Adults: Incidence, Predictors and Consequences. Acta Anaesthesiologica Scandinavica, 60, 1059-1066. https://doi.org/10.1111/aas.12717

[13] Kim, H.J., Kim, D.K., Kim, H.Y., et al. (2015) Risk Factors of Emergence Agitation in Adults Undergoing General Anesthesia for Nasal Surgery. Clinical and Experimental Otorhinolaryngology, 8, 46-51. https://doi.org/10.3342/ceo.2015.8.1.46

[14] Lepousè, C., Lautner, C.A., Liu, L., Gomis, P. and Leon, A. (2006) Emergence Delirium in the Post-Anaesthesia Care Unit. British Journal of Anaesthesia, 96, 747-753. https://doi.org/10.1093/bja/ael094

[15] Abdulatif, M., Ahmed, A., Mukhtar, A., et al. (2013) The Effect of Magnesium Sulphate Infusion on the Incidence and Severity of Emergence Agitation in Children Undergoing Adenotonsillectomy Using Sevoflurane Anaesthesia. Anaesthesia, 68, 1045-1052. https://doi.org/10.1111/anae. 12380 
[16] Wu, C.L. and Raja, S.N. (2011) Treatment of Acute Postoperative Pain. The Lancet, 377, 2215-2225. https://doi.org/10.1016/S0140-6736(11)60245-6

[17] Kurabe, M., Furue, H. and Kohno, T. (2016) Intravenous Administration of Lidocaine Directly Acts on Spinal Dorsal Horn and Produces Analgesic Effect: An in Vivo Patch-Clamp Analysis. Scientific Reports, 6, Article No. 26253. https://doi.org/10.1038/srep26253

[18] Vigneault, L., Turgeon, A.F., Côté, D., Lauzier, F., Zarychanski, R., Moore, L., McIntyre, L.A., Nicole, P.C. and Fergusson, D.A. (2011) Perioperative Intravenous Lidocaine Infusion for Postoperative Pain Control: A Meta-Analysis of Randomized Controlled Trials. The Canadian Journal of Anesthesia, 58, 22-37. https://doi.org/10.1007/s12630-010-9407-0

[19] Wu, C.L. and Liu, S.S. (2009) Intravenous Lidocaine for Ambulatory Anesthesia: Good to Go or Not So Fast? Anesthesia \& Analgesia, 109, 1718-1719.

https://doi.org/10.1213/ane.0b013e3181bbc6e1

[20] Choi, K.W., Nam, K.H., Lee, J.R., et al. (2017) The Effects of Intravenous Lidocaine Infusions on the Quality of Recovery and Chronic Pain after Robotic Thyroidectomy: A Randomized, Double-Blinded, Controlled Study. World Journal of Surgery, 41, 1305-1312. https://doi.org/10.1007/s00268-016-3842-1

[21] Ely, E.W., Truman, B., Shintani, A., et al. (2003) Monitoring Sedation Status over Time in ICU Patients: Reliability and Validity of the Richmond Agitation-Sedation Scale (RASS). JAMA, 289, 2983-2991. https://doi.org/10.1001/jama.289.22.2983

[22] De Oliveira, G.S., Ahmad, S., Fitzgerald, P.C., et al. (2011) Dose Ranging Study on the Effect of Preoperative Dexamethasone on Postoperative Quality of Recovery and Opioid Consumption after Ambulatory Gynaecological Surgery. British Journal of Anaesthesia, 107, 362-371. https://doi.org/10.1093/bja/aer156

[23] De Oliveira, G.S., Fitzgerald, P., Streicher, L.F., Marcus, R.J. and McCarthy, R.J. (2012) Systemic Lidocaine to Improve Postoperative Quality of Recovery after Ambulatory Laparoscopic Surgery. Anesthesia \& Analgesia, 115, 262-267. https://doi.org/10.1213/ANE.0b013e318257a380

[24] Lee, W.K., Kim, M.S., Kang, S.W., Kim, S. and Lee, J.R. (2015) Type of Anaesthesia and Patient Quality of Recovery: A Randomized Trial Comparing Propofol-Remifentanil Total IV Anaesthesia with Desflurane Anaesthesia. British Journal of Anaesthesia, 114, 663-668. https://doi.org/10.1093/bja/aeu405

[25] Moro, E.T., Ferreira, M.A., Gonçalves, R.D., Vargas, R.C., Calil, S.J., Soranz, M.A. and Bloomstone, J. (2020) The Quality of Recovery after Dexamethasone, Ondansetron, or Placebo Administration in Patients Undergoing Lower Limbs Orthopedic Surgery under Spinal Anesthesia Using Intrathecal Morphine. A Randomized Controlled Trial. Anesthesiology Research and Practice, 2020, Article ID: 9265698. https://doi.org/10.1155/2020/9265698

[26] Na, S.H., Jeong, K.H., Eum, D., Park, J.H. and Kim, M.S. (2018) Patient Quality of Recovery on the Day of Surgery after Propofol Total Intravenous Anesthesia for Vitrectomy: A Randomized Controlled Trial. Medicine, 97, e12699. https://doi.org/10.1097/MD.0000000000012699

[27] Veyckemans, F. (2001) Excitation Phenomena during Sevoflurane Anaesthesia in Children. Current Opinion in Anesthesiology, 14, 339-343. https://doi.org/10.1097/00001503-200106000-00010

[28] Lindenmayer, J.P. (2000) The Pathophysiology of Agitation. The Journal of Clinical Psychiatry, 61, 5-10.

[29] Hughes, C.G., Morandi, A., Girard, T.D., Riedel, B., Thompson, J.L., Shintani, A.K., 
Pun, B.T., Ely, E.W. and Pandharipande, P.P. (2013) Association between Endothelial Dysfunction and Acute Brain Dysfunction during Critical Illness. Anesthesiology, 118, 631-639. https://doi.org/10.1097/ALN.0b013e31827bd193

[30] Rim, J.C., Kim, J.A., Hong, J.I., et al. (2016) Risk Factors of Emergence Agitation after General Anesthesia in Adult Patients. Anesthesia and Pain Medicine, 11, 410-416.

https://doi.org/10.17085/apm.2016.11.4.410

[31] Jakub, K., Maciej, K., Maciej, B., et al. (2010) Incidence and Predictors of Delirium after Cardiac Surgery: Results from the IPDACS Study. Journal of Psychosomatic Research, 69, 179-185. https://doi.org/10.1016/j.jpsychores.2010.02.009

[32] McLott, J., Jurecic, J., Hemphill, L., et al. (2013) Development of an Amygdalocentric Neurocircuitry-Reactive Aggression Theoretical Model of Emergence Delirium in Posttraumatic Stress Disorder: An Integrative Literature Review. AANA Journal, 81, 379-384.

[33] Cohen, S.P. and Mao, J. (2003) Is the Analgesic Effect of Systemic Lidocaine Mediated through Opioid Receptors? Acta Anaesthesiologica Scandinavica, 47, 910-911. https://doi.org/10.1034/j.1399-6576.2003.00163.x

[34] Abelson, K.S. and Hoglund, A.U. (2002) Intravenously Administered Lidocaine in Therapeutic Doses Increases the Intraspinal Release of Acetylcholine in Rats. Neuroscience Letters, 317, 93-96. https://doi.org/10.1016/S0304-3940(01)02440-5

[35] Nagy, I. and Woolf, C.J. (1996) Lignocaine Selectivity Reduces C Fibre Evoked Neuronal Activity in Rat Spinal Cord in Vitro by Decreasing N-methyl-D-aspartate and Neurokinin Receptor-Mediated Postsynaptic Depolarizations; Implications for the Development of Novel Centrally Acting Analgesics. Pain, 64, 59-70. https://doi.org/10.1016/0304-3959(95)00072-0

[36] Chai, W., Sun, X., et al. (2010) Emergence Agitation in Adults: Risk Factors in 2,000 Patients. The Canadian Journal of Anesthesia, 57, 843-848.

https://doi.org/10.1007/s12630-010-9338-9

[37] Kim, M.H., Oh, A.Y., Jeon, Y.T., Hwang, J.W. and Do, S.H. (2012) A Randomized Controlled Trial Comparing Rocuronium Priming, Magnesium Pre-Treatment and a Combination of the Two Methods. Anaesthesia, 67, 748-754. https://doi.org/10.1111/j.1365-2044.2012.07102.x

[38] Elsery, E.H. (2017) Post-Operative Agitation in Adults, Factors, Possible Mechanisms and Prevention. Anesthesiology and Clinical Science Research, 1, 1-3.

[39] Tauzin-Fin, P. and Bernard, O. (2014) Benefits of Intravenous Lidocaine on Post-Operative Pain and Acute Rehabilitation after Laparoscopic Nephrectomy. Journal of Anaesthesiology Clinical Pharmacology, 30, 366-372. https://doi.org/10.4103/0970-9185.137269

[40] Polat, R., Peker, K., Baran, I., et al. (2015) Comparison between Dexmedetomidine and Remifentanil Infusion in Emergence Agitation during Recovery after Nasal Surgery: A Randomized Double-Blind Trial. Anaesthesist, 64, 740-746. https://doi.org/10.1007/s00101-015-0077-8

[41] Kim, S.Y., Kim, J.M., Lee, J.H., et al. (2013) Efficacy of Intraoperative Dexmedetomidine Infusion on Emergence Agitation and Quality of Recovery after Nasal Surgery. British Journal of Anaesthesia, 111, 222-228.

https://doi.org/10.1093/bja/aet056

[42] Kim, D., Doo, A.R., Lim, H., et al. (2013) Effect of Ketorolac on the Prevention of Emergence Agitation in Children after Sevoflurane Anesthesia. Korean Journal of Anesthesiology, 64, 240-245. https://doi.org/10.4097/kjae.2013.64.3.240

[43] Rahimzadeh, P., et al. (2014) Sevoflurane-Induced Emergence Agitation in Child- 
ren; Propofol-Lidocaine and Thiopental Sodium-Lidocaine: A Randomized Controlled Trial. Iranian Red Crescent Medical Journal, 16, e16388. https://doi.org/10.5812/ircmj.16388

[44] Christian, P. (2018) Laparoscopic Appendectomy-A Retrospective, Single-Centre Experience. BMC Anesthesiology, 18, 88.

https://doi.org/10.1186/s12871-018-0545-1

[45] Ho Jang, Y. and Ryung, S. (2005) Intravenous Lidocaine Does Not Reduce Emergence Agitation or Pain after Sevoflurane Anesthesia in Children. Korean Journal of Anesthesiology, 49, 14-19. https://doi.org/10.4097/kjae.2005.49.6.S14

[46] Myles, P.S., Myles, D.B., Galagher, W., Chew, C., MacDonald, N. and Dennis, A. (2016) Minimal Clinically Important Difference for Three Quality of Recovery Scales. Anesthesiology, 125, 39-45. https://doi.org/10.1097/ALN.0000000000001158

[47] Wang, Q., Ding, X., Huai, D., Zhao, W., Wang, J. and Xie, C. (2020) Effect of Intravenous Lidocaine Infusion on Postoperative Early Recovery Quality in Upper Airway Surgery. Laryngoscope. https://doi.org/10.1002/lary.28594

[48] Lee, U., Choi, Y.J., Choi, G.J. and Kang, H. (2017) Intravenous Lidocaine for Effective Pan Relief after Bimaxillary Surgery. Clinical Oral Investigations, 21, 2645-2652.

https://doi.org/10.1007/s00784-017-2066-6

[49] Kim, M.H., Kim, M.S., Lee, J.H., Kim, S.T. and Lee, J.R. (2018) Intravenously Administered Lidocaine and Magnesium during Thyroid Surgery in Female Patients for Better Quality of Recovery after Anesthesia. Anesthesia \& Analgesia, 127, 635-641. https://doi.org/10.1213/ANE.0000000000002797

[50] Franck, M., Radtke, F.M., Apfel, C.C., et al. (2010) Documentation of Post-Operative Nausea and Vomiting in Routine Clinical Practice. Journal of International Medical Research, 38, 1034-1041. https://doi.org/10.1177/147323001003800330

[51] Kaba, A., Laurent, S.R., Detroz, B.J., et al. (2007) Intravenous Lidocaine Infusion Facilitates Acute Rehabilitation after Laparoscopic Colectomy. Anesthesiology, 106, 11-18. https://doi.org/10.1097/00000542-200701000-00007 